\section{Filtration apparatus for protein extraction from urine}

K. D. BAGSHAWE, J. E. KEMBLE, and M. G. THOMAS From the Edgar Laboratory, Department of Medicine, Charing Cross Hospital Medical School, London

The high pressure filtration apparatus described here was developed for the concentration of gonadotrophic hormones from urine by absorption onto and elution from kaolin (Scott, 1940; Dekanski, 1949). It is also suitable for the extraction of other proteins from urine by similar processes and for ultrafiltration.

\section{MECHANICAL ARRANGEMENT}

The apparatus consists of a source of oil-free compressed air $(60-80 \mathrm{lb}$./sq. in.) connected to four stainless steel filtration vessels, each of $2.5 \mathrm{l}$. capacity via individual

Received for publication 22 July 1964.

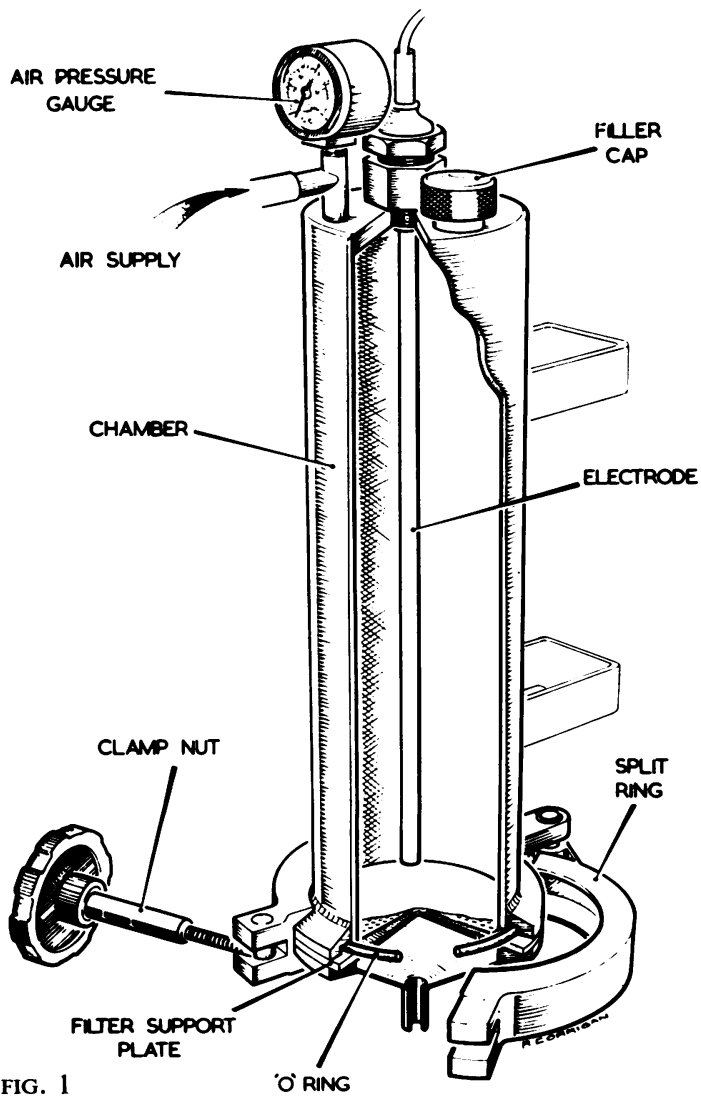

three-way magnetic control valves. The filter paper is supported on a perforated steel disc which fits flush into a recess in a stainless steel plate. The plate is grooved and drilled to allow the filtrate to flow through a series of holes into the collecting cup. The plate forms a tight seal when pressed against the O-ring inset in the base of the cylinder and the corresponding rim of the collecting cup by the action of the split clamp ring. The top plate of the filtration vessels is fitted with a filling port, pressure gauge, air inlet, and an electrode clamping ring which permits adjustment of the electrode position. The electrode consists of a mild steel rod which is totally enclosed by insulating material except at its lower end which is platinized to prevent oxidation.

The apparatus has been assembled in a cabinet covering the compressor but where a line source of compressed air is available the apparatus could be wall mounted.

\section{ELECTRICAL CIRCUIT}

The operations of pressurization and decompression of the vessels are controlled from an electronic control cabinet. Each vessel is controlled by its own thyratron connected in series with a relay which in turn energises the air valve or solenoid. The phasing is such that when a relay is energised the air valve pressurizes its respective chamber. The control circuit of each thyratron consists of a $4 \mathrm{v}$. stabilized supply voltage feeding a simple potential divider. The upper limb of this divider is the resistance between the electrode and vessel wall, and the lower limb is a fixed resistor. The centre of the divider is suitably connected to the thyratron's control grid. So long as the electrode resistance is smaller than approximately $1 \mathrm{meg}$. $\mathrm{Ohm}$, i.e., submerged in liquid, the thyratron at the start

FIG. 1. Cut-away diagram of pressure filtration chamber.

FIG. 2. Complete apparatus showing four cylinders with solenoid valves mounted on a cabinet.

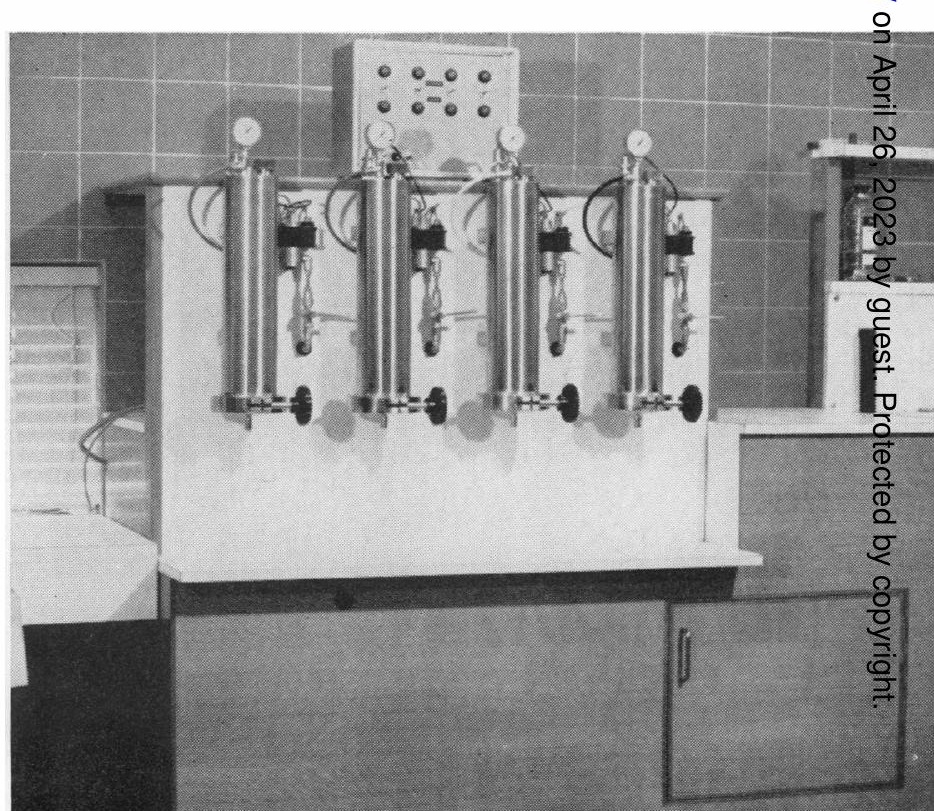


of the cycle is held 'off'. When, however, the electrode appears above the surface of the liquid, the resistance rapidly approaches infinity and so 'fires' the thyratron which, via the relay, decompresses the chamber. This circuit has the following safety features:

1 It is impossible to pressurize a vessel until it contains a minimum quantity of liquid. 2 Once a filtering cycle has been completed the cycle cannot be re-started until the vessel is refilled and the switch set to 'discharge' and then to 'charge'. 3 A vessel can be discharged safely at any time irrespective of the fluid level by a manual override. 4 Two coloured lights and a pressure gauge clearly show the state of each vessel at all times. 5 The maximum electrode current is 4 microamps.

\section{OPERATION}

The $p \mathrm{H}$ of the 24- or 48-hour urine collection is adjusted to 4.5 and standard amounts of kaolin and hyflo-supercell are added, stirred, and allowed to settle. The mixture is poured into the filtration chamber. The screw cap is fitted to the filling port and the appropriate switch is closed. A red warning light indicates that the vessel is pressurized and filtration proceeds. As the liquid drops below the level of the electrode the circuit changes to 'discharge'. The air control valve then shuts off and the chamber discharges to atmosphere. This is indicated by the red light going out and the green light being illuminated. After flicking the operating switch to discharge the washing solution is admitted through a funnel fitted with a spray to avoid holing the kaolin cake. Filtration, washing, and elution can be completed in six to 12 minutes. The eluate is collected in $550 \mathrm{ml}$. centrifuge vessels in which the stages of reacidification, acetone precipitation, centrifugation, and drying are completed.

COMMENTS

The apparatus is similar in general plan to that described by Albert and Rogers (1951) and Albert (1955), but differs in two respects. One is the use of a filtration chamber of smaller diameter so that for a given amount of kaolirw the cake is thicker. Whilst this produces a somewha 5 slower rate of filtration it ensures an adequate and evenexposure of the cake to the eluting solutions. The othet difference lies in the use of a fluid level device for the control of the air inlet valve instead of the air flow valve used by Albert. With an air flow valve the air inlet only closes when the kaolin cake starts to dry out. Drying ofo the kaolin may lead to cracking and inefficient elution and the present system ensures that the cake is kept moist At the end of the final washing stage the fluid level controf device can be by-passed to ensure that all the washing solution is blown through.

Recovery experiments using this apparatus will be reported elsewhere.

The construction of this apparatus was made possible b\$ a grant from the Medical Research Council.

\section{REFERENCES}

Albert, A. (1955). Proc. Mayo Clin., 30, 552. and Rogers, D. A. (1951). J. Lab. clin. Med., 37, 485.

Dekanski, J. (1949). Brit. J. exp. Path., 30, 272. Scott, L. D. (1940). Ibid., 21, 320. 